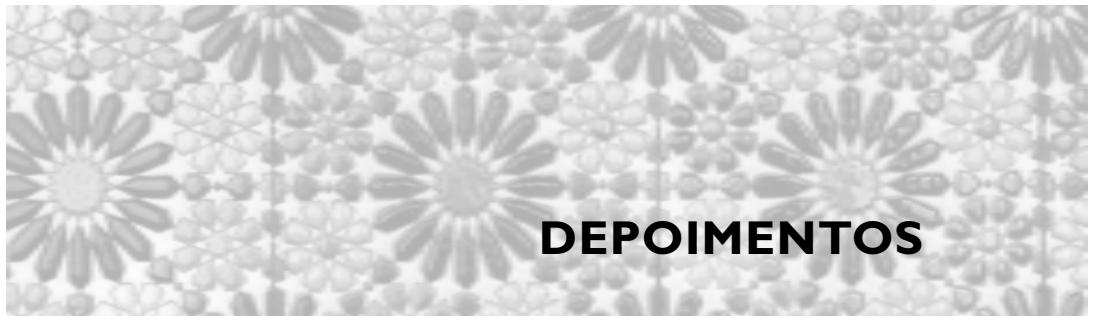

\title{
A saúde entre o Estado e a sociedade
}

\section{Health: between the State and society}

Entrevista com Mozart Abreu Lima/Interview with Mozart Abreu Lima

SHIS - QL 20, conjunto 5 casa 14 Lago Sul

71650-155 Brasília - DF Brasil

LIMA, M. A.: 'A saúde entre o Estado e a sociedade'. Entrevista concedida a Carlos Fidelis Pontwe. História, Ciências, Saúde - Manguinhos, vol. 10 (suplemento 2): 743-70, 2003.

Ele testemunhou, 'de dentro', os estertores da ditadura militar brasileira, durante o governo João Baptista Figueiredo. Foi o "ministro interno" da Saúde do Brasil, nas palavras do próprio titular da pasta, Waldir Arcoverde. Respondeu, no Ministério da Saúde, por importantes mudanças, e para isso enfrentou com a verve nordestina as contínuas ameaças e pressões da chamada comunidade de informações, que à época governava o Brasil com mão de ferro. Mozart Abreu Lima foi um dos principais estrategistas da saúde pública brasileira no período de passagem da ditadura para a lenta e gradual restauração do Estado de direito. Para a cadeira de secretário geral do Ministério da Saúde levou a inteligência que o destacou na elaboração do plano diretor da Central de Medicamentos, a Ceme, e a cultura de gestão descentralizada e participativa experimentada na Superintendência para o Desenvolvimento do Nordeste, a Sudene.

Embora se apresente como um homem de esquerda, não hesita em aplaudir a política industrial implantada pelos governos militares, em especial a partir da administração Geisel. Nacionalista contumaz, Mozart Abreu Lima fez história na Fiocruz, como um dos mentores da criação do Instituto Nacional de Controle de Qualidade (INCQ). Principal responsável pela extraordinária logística que viabilizou a realização dos dias nacionais de vacinação, modelo de imunização hoje mundialmente consagrado, nesta entrevista concedida a Carlos Fidélis Ponte, pesquisador da Casa de Oswaldo Cruz, ele desvenda os bastidores de sua experiência no poder, revela esquemas de corrupção na fiscalização da saúde, apresenta conceitos de gestão pública e critica o Brasil das instituições descartáveis, do Estado empobrecido e desmantelado, de caso pensado, transformado em mercado de fast-food.

PALAVRAS-CHAVE: imunização, vacina, pólio, Ceme, saúde pública.

LIMA, M. A.: 'Health: between the State and society'. Interview conducted by Carlos Fielis Ponte. História, Ciências, Saúde - Manguinhos, vol. 10 (supplement 2): 743-70, 2003.

He was an inside witness to the death throes of Brazil's military dictatorship, under the João Baptista Figueiredo administration. He was "internal minister" of Health, in the words of the official Minister himself, Waldir Arcoverde. Within this ministry, he was responsible for important changes and as a result had to rely on his Northeastern vitality to cope with the constant threats and pressures brought to bear by the so-called "information community," then ruling Brazil with an iron fist.

Mozart Abreu Lima was one of the country's key public health strategists in the period leading from dictatorship to Brazil's slow and gradual return to the rule of law. When he took office as secretary general of the Health Ministry, he brought with him the sharp intelligence already demonstrated during development of a master plan for the Central de Medicamentos (Ceme), a centralized drug administration with broad powers. He also came equipped with a culture of decentralized, participative management, acquired at Sudene (Superintendência para o Desenvolvimento do Nordeste), the federal agency responsible for development of the Brazilian Northeast.

Although he considers himself a man of the left, he has no qualms about applauding the industrial policy inaugurated by Brazil's military governments, especially dating from the Geisel administration. A contumacious nationalist, Mozart Abreu Lima made history at Fiocruz as one of the mentors behind creation of the National Quality Control Institute (Instituto Nacional de Controle de Qualidade/INCQ). His was the main hand behind the extraordinary logistics involved in introducing National Vaccination Days, now a worldwide model in immunization approaches. In this interview given to Carlos Fidélis Pontes, a researcher at Casa de Oswaldo Cruz Mozart goes behind the scenes of his experience in power, reveals corruption schemes in the area of health surveillance, shares concepts on public management, and criticizes the Brazil of disposable institutions, of an impoverished, dismantled State, transformed into a fast-food market.

KEYWORDS: immunization, vaccine, polio, CEME, Public Health, Public Health as a mission 


\author{
"Tentaram me \\ tirar muitas \\ vezes, porque eu \\ era a mola que \\ fazia o ministério \\ funcionar, e, por \\ isso, objeto da \\ apreciação da \\ comunidade de \\ informações. $\mathrm{O}$ \\ ministro foi \\ muitas vezes \\ pressionado por \\ escalões \\ superiores do \\ SNI para me tirar \\ do ministério. Era \\ a maior tensão."
}

O senhor foi secretário geral do Ministério da Saúde na gestão de Waldir Arcoverde, durante o governo Figueiredo, de 1979 a 1985. Em que situação o senhor encontrou o ministério e qual era o grande desafio a vencer naquela gestão pública da saúde?

Chegamos ao ministério com a disposição de renovar inteiramente a forma de trabalhar, que então se sustentava em uma visão exclusivista da atenção à saúde. Entendíamos a saúde como um componente que não dependia só de um setor. Eu, particularmente, vinha de uma escola que fazia muita crítica a essa visão do ministério. Minha origem era a Divisão de Saúde da Sudene, um grupo com enormes conflitos em relação à estrutura tradicional do ministério, estabelecida para continuar assim a vida inteira: grandes programas, estruturas pesadas, sem mobilidade e sem capacidade de articulação para uma ação direta. Quando fui escolhido secretário geral, os mais tradicionalistas reagiram: "Isso já não é mais uma abertura. É um arrombamento."

\section{OMinistério da Saúde não se articulava com outros ministérios e outras áreas do governo?}

O nível de articulação era muito baixo. Aliás, este é um vício que permanece na estrutura do Ministério da Saúde, essa visão voltada para o seu umbigo, de que a saúde é que tem que cuidar da saúde. Tanto que a nossa Constituição abre toda uma nova perspectiva para a saúde e até hoje o ministério, como gestor nacional, não organizou nenhuma estrutura intersetorial. Isso existiu na nossa administração. E hoje também não tem mais. Hoje o que temos é a estrutura do Conselho Nacional de Saúde, com suas comissões intersetoriais, e só.

Por que a gestão da saúde pública exige uma estrutura intersetorial?

A desarticulação é um defeito do setor... O setor acredita que ele pode, sozinho, resolver as coisas. E, se não consegue, queixa-se que não pode resolver porque não depende só dele. Contudo, não procura os mecanismos operacionais para resolver essa dificuldade. Quer encaixar num único setor a solução de todos os problemas de um componente complexo da vida humana, que é a saúde.

\section{Que mudanças seu grupo trazia para o Ministério da Saúde?}

Chegamos como um grupo que veio para mudar, apesar do reconhecimento de todas as limitações que teríamos pela frente, como dificuldades orçamentárias e de conjuntura. Éramos uma equipe formada por um grupo específico do Nordeste e um grupo de experimentação do Rio Grande do Sul, de onde vinha o Waldir Arcoverde. Uma equipe de nordestinos e sulistas, que entrou disposta a aproveitar os quadros tradicionais do ministério. 
Qual a origem da equipe anterior? A Faculdade de Saúde Pública de São Paulo?

É. Mas não fazíamos críticas à faculdade em si. Nem aos componentes dessa base. Criticávamos a administração de Paulo de Almeida Machado, muito autoritária, que não deixava aparecerem os diferentes pensamentos existentes dentro do próprio Ministério da Saúde. Perseguiam, invariavelmente, aqueles que não pensavam da mesma maneira. Eu mesmo fui vítima disso. O gabinete ministerial — que eram o ministro e a filha do ministro, com enorme poder, como sua secretária particular - tinha uma personalidade centralizadora. Onde estavam os elementos que pensavam diferente? Estavam nas diferentes estruturas. Na Sucam, na Fundação SESP, na Fundação Oswaldo Cruz. Todos eram um pouco vítimas. A Fundação Oswaldo Cruz, até certo ponto, escapava disso porque seu dirigente, na época, tinha forças junto ao ministro Delfim Neto para empreender o projeto de reforma da Fiocruz.

\section{O Vinícius da Fonseca?}

O Vinícius da Fonseca (presidente da Fiocruz, de 1975 a 1979), um administrador inovador, que tinha o apoio político e financeiro do Reis Veloso (João Paulo dos Reis Veloso, ex-ministro do Planejamento). Por isso ele pôde se mover com liberdade dentro da Fiocruz. Mas as outras estruturas eram conduzidas com mão de ferro.

\section{Mas era tão controlado assim?}

Bom exemplo é o da 6a Conferência Nacional de Saúde (Brasília, agosto de 1977), em que a equipe do Ministério da Agricultura foi expulsa pelo Ministério da Saúde, simplesmente porque defendia algumas ações na área da saúde animal! Era um ambiente extremamente pesado. Quando comecei o trabalho de persuasão dentro do ministério, fazia enormes reuniões, com centenas de pessoas, para motivá-las a reagir, a levantar o dedo numa assembléia. Minha estratégia inicial era ir conquistando quadros a partir daqueles que tinham a coragem de levantar o dedo numa assembléia do Ministério da Saúde. Todas as minhas equipes, dos chamados GTs, foram compostas, essencialmente, por essas pessoas. Um bocado de gente nova.

\section{Mas com que apoio político e financeiro era possível promover essa mudança?}

Também com o apoio do Reis Veloso. O dinheiro vinha do Instituto de Pesquisa Econômica Aplicada (IPEA), ligado à Secretaria de Planejamento. Esses jovens, movimentados pela Seplan, eram vistos como subversivos, porque eram em geral ligados aos grupos de esquerda da época. Estavam saindo das universidades na década de 1970 e no início dos anos 1980, já como profissionais, vinham do movimento contrário à ditadura militar. Eram pessoas que agiam dentro do chamado "Partidão do Reis Veloso". O próprio Veloso 
“Ao invés de uma reforma administrativa, que demandaria tempo e energia, fizemos uma estrutura matricial. Deixa lá a estrutura tradicional e vamos montar uma estrutura de projetos. E assim você vai saindo da estrutura tradicional." dizia: "Deixa agir dentro do IPEA. Aqui é o meu partidão. São os canais que me possibilitam escutar a universidade, porque eu não posso fazer isso direto, então são eles que fazem esse intercâmbio, me trazem as coisas como estão, fora do nosso próprio pensamento." Isso, num ambiente de abertura lenta, gradual e segura, que eram os três princípios do Geisel. O Reis Veloso foi uma peça-chave nisso. Ele buscava, através da multiplicidade do IPEA, ouvir esse segmento de pessoas que estavam por aí, pelas instituições. Não tinha o vezo ideológico para impedi-los de continuar o trabalho.

\section{O senhor não sofreu pressões por absorver esses jovens?}

A primeira veio do coronel do Serviço Nacional de Informações (SNI), que me exigiu botar todos eles para fora, já que eram todos comunistas. E tínhamos a Divisão de Segurança Interna (DSI). A indicação de qualquer membro da equipe tinha que passar pela DSI e o SNI. Aí, nós dissemos: "Espera aí, coronel. A responsabilidade de administrar aqui é nossa. Nós temos que encontrar soluções para administrar a saúde nesse país. O senhor dá os seus elementos de convicção, nós ponderamos e consideramos, mas a decisão é nossa."

\section{E como foi esta relação?}

Muito tensa, o tempo todo. Tentaram me tirar muitas vezes, porque eu era a mola que fazia o ministério funcionar, e, por isso, objeto da apreciação do coronel da DSI. Ele fazia intrigas contra mim para o próprio ministro, que dizia: "Aqui tem o ministro externo, que sou eu, responsável pelas grandes políticas, e tem o ministro interno, que é o dr. Mozart. Portanto, a condução interna é dele." O ministro foi muitas vezes pressionado por escalões superiores do próprio SNI para me tirar do ministério. Era a maior tensão. Eles traziam relatórios sobre pessoas ligadas à Secretaria Geral, para minar minha liderança, exigiam demissões. Eu nunca atendi.

\section{Assim, ninguém mais iria levantar o dedo, não é mesmo?}

Exatamente. O ministério começando a fazer assembléias gigantescas, com um secretário geral falante, estimulando o questionamento de cada um. E isso era importante, uma maneira de adquirir conhecimento, escolher rumos, já que eu tinha dúvidas sobre a possibilidade de sustentar inovações em uma estrutura tradicional, engessada e extremamente dogmática. Esse era o conflito. Com os profissionais, mesmo essas pessoas dogmáticas, nós convivemos a vida inteira. Não foram perseguidos. Foram colocados em funções menos importantes para desenvolver os programas, integrar áreas, mas sempre respeitando suas atividades, seus campos. Ninguém foi perseguido. A equipe de São Paulo voltou porque quis, decisão deles. 
Qual foi o primeiro embate com a cultura existente no ministério?

A nossa ida para o ministério visava adotar os ares da abertura política, de consultar instituições da sociedade, de buscar elementos, na sociedade, para compor equipes, elementos que vinham com outras informações e outras experiências, diferentes daquelas do núcleo segmentado que tradicionalmente atuava no ministério. Essa foi a nossa chegada.

\section{Qual era a orientação inicial? Quais eram os planos da nova equipe?}

Primeiro houve um fato fundamental: o discurso de posse do ministro. Nossa idéia era tomar o discurso como plano de metas. Disse: "Vamos analisar o discurso do ministro e, pela primeira vez, fazer do discurso, uma prática." Ou seja, as palavras ditas pelo ministro, na emoção da posse, têm que ter significação plena na realidade. E o discurso era muito bem-feito. Foi elaborado por uma equipe sob o comando do

"Enfrentamos a decisão de fazer um dia nacional de imunização contra a pólio com enormes problemas de logística.

Precisávamos de 35 milhões de doses de vacinas. Onde comprar? Onde estocar? Como controlar a qualidade?"
Moacir Scliar, que é um escritor, um poeta.

Do Sul.

Do Rio Grande do Sul, exato. Pegamos esse discurso e o abrimos programaticamente. Na primeira hora. Todas aquelas idéias expostas foram transformadas em grandes linhas programáticas. Se havia a questão de vacina, pró-imune; a questão da vigilância sanitária de medicamentos, pró-controle; a questão relativa aos serviços básicos, pró-saúde.

\section{Foram constituídos programas especiais para cada área?}

Linhas programáticas, que passaram a orientar a montagem de uma estrutura matricial para conduzir aquilo. Ao invés de passarmos por um projeto de reforma administrativa, que demandaria tempo e energia, fizemos uma estrutura matricial, que respeitava a estrutura anterior. Deixa lá a estrutura tradicional e vamos montar uma estrutura de projetos. E assim você vai saindo da estrutura tradicional.

\section{Essa estratégia se associava à da mobilização de novos quadros?}

As organizações formais eram estoques de idéias profissionais e de experiências. Optamos por não promover uma reforma administrativa, por não modificar os órgãos. Isso só iria nos dar dor de cabeça, gerar resistências e, na realidade, não significaria nada para a sociedade, que é quem interessa. O nosso sonho era modificar as condições da sociedade. Fazer com que a sociedade viesse a participar ativamente de seus problemas. Por isso a estratégia da mobilização era fundamental. Isso, como você sabe, num momento em que a mobilização era muito difícil.

\section{Como foi articulada, então, a nova estrutura matricial?}

Definidas as linhas programáticas, preparou-se um trabalho que foi levado ao grupo de condução do ministério — ministro e seus principais 
assessores. O grupo bateu o martelo: vamos conquistar as poderosas instituições do Ministério da Saúde para esse trabalho. Fundação SESP, Sucam, Fundação Oswaldo Cruz. Essas eram e sempre foram as grandes e poderosas no ministério. Conquistar para essa nova forma de fazer e pensar. O núcleo das ações programáticas trabalhou com comitês gestores de cada área, ainda do âmbito do Ministério da Saúde. Era preciso dar unidade tática de ação ao Ministério da Saúde. Como administrador sempre defendi que, mesmo possuindo as melhores estratégias, se você não tiver disciplina tática não irá conseguir administrar nada. As grandes estratégias alcançam sucesso quando você tem boa unidade tática. Que é o que faz alterar as ações. Para isso a gente precisou conquistar para os novos comitês os corações e as mentes das pessoas que estavam dentro dessas enormes caixas. Fundação SESP? Então a Fundação SESP indica representantes para essa área. Quem são eles? Sucam? E assim vai...

\section{Os comitês eram os canais de articulação dentro e fora do ministério?}

Exatamente. Mas antes era preciso organizar internamente, para quando saíssemos para discutir fora, tivéssemos unidade. Quer dizer, o ministério não sairia mais por aí, cada um com seu projeto específico, indo buscar dinheiro no FAT, no FAE etc. Precisávamos sair com unidade para qualquer negociação. Se a Fundação Oswaldo Cruz tinha um projeto que considerava importante, ela tinha que trazer o projeto para dentro do comitê, justificar sua viabilidade e integrá-lo operacionalmente com as demais unidades do ministério, no que elas tinham de melhor. E, a partir daí, nós íamos buscar lá fora o apoio, financeiro ou institucional, para realizar.

\section{Ecomofuncionaram?}

Os comitês criados na nossa gestão promoviam essa unidade. Cada comitê elaborou um documento de política específica de sua área, e à luz das grandes linhas doutrinárias derivadas do discurso os comitês se juntaram, discutiram uma proposta e voltaram de novo à chamada cúpula do ministério. Batido o martelo, cada comitê passava a ter o papel de gestor daquela ação de sua área. Cumpria, prestava contas ao ministro. Mas o ministro não se metia na operação.

\section{Uma vez aprovada...}

A gestão era do comitê. E quem coordenava o comitê era o órgão melhor vinculado àquela área de ação. No caso da imunização, o Comitê de Controle de Doenças. A Secretaria Nacional de Ações Básicas, comandada pelo dr. Risi (João Baptista Risi Junior), coordenava o comitê. E a sua estrutura específica iria se responsabilizar por fazer essa linha caminhar. A Secretaria Geral, por sua vez, ocupada por mim, tinha o papel de fazer com que não faltassem meios a esse gestor. O que era um gestor? O que era um secretário nacional, numa enorme estrutura e com pouco dinheiro? Por isso, na Secretaria Geral, tínhamos os GTs, 
"Campanha

versus rotina.

Essas são

questões que não

têm nada a ver

com a realidade

do cidadão. $\mathrm{O}$

cidadão não pode

ser privado de

um benefício

porque você diz:

eu só posso fazer

via campanha, ou

via rotina." encarregados de dar suporte a essas atividades. Os GTs eram os elementos que viabilizavam meios como orçamento e finanças, recursos humanos, capacitação, informações.

\section{Os GTs, então, apoiavam os comitês?}

Cada comitê se apoiava em ene funções, de acordo com sua necessidade. Se a função era orçamentária, financeira, O GT correspondente ia dar sustentação à ação específica. Porque, logicamente, uma linha programática se desdobrava em um conjunto enorme de ações. Você tinha que comprar vacina, armazenar vacina, distribuir, montar a rede de frio. Uma série de ações a serem desenvolvidas. $\mathrm{O}$ nosso objetivo era que não faltassem meios para conduzir isso. Para que cada um tivesse plena possibilidade de realizar seus cronogramas e cumprir sua missão. Não é à toa que chegamos no ministério em dezembro de 1979 e, já em junho de 1980, estávamos realizando o primeiro Dia Nacional de Vacinação.

\section{É, foi muito rápido...}

E tudo isso acontecia mais ou menos no escuro. Naquela época, não sabíamos, ainda, onde comprar vacina, com qualidade, naquele volume. Onde armazenar, como conservar. A equipe tinha que identificar os pontos falhos da sua ação e a Secretaria Geral atuava para ajudá-la a resolver esse problema. Rede de frio: precisa dotar a secretaria estadual de uma rede para armazenamento de vacinas. Dotar os centros de saúde de refrigeradores. Isso não era pensado antes. Não existia.

Mas é uma coisa engraçada, porque a cerveja sempre gelada, existia.

Tinha no bar da esquina. Mas não tinha refrigerador na secretaria. A grande verdade é que nós enfrentamos a decisão de fazer um dia nacional de imunização contra a pólio com enormes problemas de logística para resolver. Nós precisávamos de 35 milhões de doses de vacina. Onde comprar? Onde estocar? Como controlar a qualidade? Então, a partir das necessidades, foram nascendo propostas de solução. E funciona assim para cada ação programática.

Assim a sua equipe sobrepôs uma estrutura matricial na estrutura formal?

E a estrutura tradicional continuou exatamente como era, não mexemos nela. Fomos buscar as potencialidades de que precisávamos em setores que o ministério pouco usava, a não ser nas campanhas. Sobretudo Fundação SESP e Fundação Oswaldo Cruz. Porque tínhamos duas fundações importantes e uma autarquia, a Sucam, também importante, porém menos flexível. E tínhamos, ainda, mais algumas campanhas remanescentes para as questões do câncer, da saúde mental. Isso tudo, a gente foi buscar lá dos idos de 1950 e reativar para ter flexibilidade de manejo de recursos que a estrutura formal não tinha. Então, por este modelo, transferíamos os recursos para esses órgãos e 
eles tinham a facilidade de manejo que não tínhamos nós, na estrutura formal, com todas as suas exigências.

Na área da imunização, a gestão que precedeu à do ministro Arcoverde defendia a ação de rotina em contraposição às grandes campanhas nacionais, que haviam sido praticamente extintas. A posição dos senhores era diametralmente oposta, portanto?

Campanha versus rotina. O que nós trazíamos de inovação para isso? Essas são questões que não têm nada a ver com a realidade do cidadão. O cidadão não pode ser privado de um benefício porque você diz: "Eu só posso fazer via campanha, ou via rotina." Todos dois têm profundos defeitos. A rotina, porque não tínhamos estrutura para implementá-la. Não tínhamos organização nem capilaridade. O ministério era centralizado, não apoiava os estados em seus objetivos de modernização técnico-administrativa. Entretanto, exigia dos estados, decidia suas normas, e os estados não tinham participação efetiva na forma de fazer. Então, esbarrávamos em uma rotina de baixíssima cobertura.

Naquela época, o município ainda não existia como instância de ação dopoderpúblico?

Poucos municípios tinham secretaria de Saúde. Talvez uns quarenta, em todo o Brasil, e com realidades muito diferentes. Nós estávamos no estágio dos estados. A discussão campanha ou rotina, então, não cabia. Tínhamos que estabelecer a melhor forma de atingir a maior cobertura possível. Portanto, era preciso mesclar os dois componentes. Tínhamos que conseguir que toda a estrutura de prestação de serviços de saúde, direta e de outros segmentos do Estado e da sociedade, participasse dos dias de vacinação. Portanto, ao mesmo tempo tinham o caráter de campanha, conferiam capilaridade às estruturas.

\section{Qual a dimensão dessa capilaridade?}

Quem comandava as equipes de vacinação nos municípios eram os serviços de saúde, em suas diferentes localidades. Neles se encontravam as vacinas, neles as vacinas eram conservadas, ou seja, nas diferentes localidades havia toda a estrutura de controle e supervisão dessas vacinas. Então dizer que os dias nacionais de imunizações são campanhas é um erro histórico. Para nós isso não tinha a menor importância. Não tínhamos o menor interesse em entrar nessa discussão, que considerávamos, já naquela época, arcaica. Quando se institui o Plano Nacional de Imunização (PNI), em 1973, já se estava considerando que havia necessidade de mudar as estratégias. 


“Trabalhamos
para imunizar
$95 \%$ da
população
brasileira pela
vacina antipólio
oral. Nosso foco
era alcançar, no
mínimo, vinte
milhões de
crianças de até
cinco anos.
Como chegar lá,
não importa. É
preciso ter
metodologias
diferenciadas, de
acordo com os
problemas de
cada região.”

“Trabalhamos

95\% da

população

brasileira pela

vacina antipólio

oral. Nosso foco

era alcançar, no

mínimo, vinte

milhões de

crianças de até

cinco anos.

Como chegar lá,

não importa. É

preciso ter

metodologias

diferenciadas, de

os

cada região."
Por que, apesar do sucesso da Campanha de Erradicação da Variola, na gestão do ministro Paulo Almeida Machado, o PNI parece ter-se esvaziado?

O PNI caiu na rotina, começou a ter o mesmo efeito que tinha antes da campanha. Respondia a demandas. Não as antecipava. O otimismo na época da criação do PNI não se devia somente à Campanha de Erradicação da Varíola. O fato novo era a Central de Medicamentos (Ceme), que gerou grande expectativa, por sua capacidade de adquirir insumos para uma ação mais forte. Antes vivíamos correndo atrás das epidemias. O Estado sempre agia no momento da epidemia e não para evitar que ela ocorresse. Aliás, o que é bem típico das campanhas agir quando o fogo já foi ateado. Precisávamos de uma ação mais sustentada, que considerasse a avaliação de risco para que o Estado se capacitasse a atuar preventivamente. Essa era a concepção orgânica do PNI. Por isso havia um conjunto de epidemiologistas, muitos deles tradicionais e experientes, outros absolutamente inovadores, envolvidos nessa discussão. Mas não era a campanha que estava em debate. O que se queria buscar era aquilo que se chama efetividade, aumento da cobertura.

\section{O dilema, então, era capacitar o Estado a formular e executar uma} politica preventiva?

Esse era o problema a resolver, e não se era campanha versus rotina. A questão era possibilitar que a estrutura central, que a inteligência do sistema, pudesse se antecipar aos problemas. Muitas pessoas não entenderam isso e chamavam a estratégia dos dias de campanha de campanhista. Que estratégia campanhista é esta? Campanhista era quando a Sucam saía com as pistolas, fazendo filas nas escolas e pau, pau, pau. Como fez contra a varíola e, depois, na própria epidemia de meningite.

\section{Como o senhor define, então, o modelo de imunização adotado em sua gestão no ministério?}

Nossa idéia era: temos que usar tudo. Escola, fila de cinema. Para onde vai a população? Por onde ela caminha? Nós temos que encontrála. E precisamos ter rotina, temos que ter serviços permanentes que não pensem apenas na demanda que chega a eles. Portanto, o Centro de Saúde deveria ampliar o seu raio de ação para fora de suas dependências. Deveria encontrar essa população que nunca vai ao serviço de saúde.

Então, em termosformais e em termos de legislação existia uma estrutura montada, mas na bora de funcionar ela ficava ensimesmada.

Antes, era como se fosse uma estratégia de guerra, mobilizada na força. Quando, ao contrário, era preciso possibilitar aos serviços de saúde liderar a saúde de suas comunidades. E é lógico que a nossa equipe no ministério trazia isso da vivência no Nordeste. Região mais difícil do país, onde a Sudene começou a trabalhar em 1967. Quando 
"Sabin nos levou a uma perda de energia enorme. Tínhamos que nos defender das acusações da imprensa, que assumiu Sabin como o prêmio Nobel do Brasil. Ele nunca teve prêmio Nobel, mas a imprensa brasileira lhe deu o Nobel. Ele era casado com a filha da condessa do Jornal do Brasil." chegou na década de 1980 as secretarias dos estados do Nordeste eram organizadas, tinham núcleo de planejamento, tinham estruturas de epidemiologia organizada. Tinha alguma coisa com que você podia contar. Outros estados também tinham, como São Paulo e Rio Grande do Sul. Mas a maioria da região Norte não tinha. Foi montado a partir de 1980. Começamos a organizar, na mesma estratégia seguida pela Sudene no Nordeste, nas outras unidades da federação. Você tinha uma base para pensar que era possível. E a atividade da Sudene era eminentemente federativa e descentralizadora. A Sudene sempre atuou com as estruturas dos estados.

\section{É esse o modelo descentralizador que seu grupo leva..}

Para dentro do ministério. Não se estava disputando mais se era campanha ou não. Você passava a ter uma visão que o administrador tem, de terminalidade. Você só consegue controlar a enfermidade se atinge, de acordo com percentuais estabelecidos, um nível de cobertura vacinal. Se não consegue, não estou dizendo que está perdendo tempo, mas não está obtendo resultado do ponto de vista da saúde pública. Você pode proteger alguns contra a doença, mas não reduz, nem elimina as epidemias. Este era o nosso foco de atuação: imunizar 95\% da população brasileira pela vacina antipólio oral. Alcançar, no mínimo, 95\% da população menor de cinco anos, que eram vinte milhões de crianças. Como você chega lá, não importa. Você tem que ter metodologias diferenciadas, de acordo com os problemas de cada região. Como atingir a população do Amazonas, um terço dela concentrada em Manaus e 70\% dispersa? Hoje já temos outros pólos de concentração, mas na época era Manaus e o resto. Como chegar nos ribeirinhos? É bem diferente de como chegar no Nordeste ou no Sul. Na idéia do dr. Sabin, a coisa era simples: entrega às Forças Armadas e eles descem de pára-quedas e saem vacinando a pulso. Ele nunca acreditou que pudéssemos fazer uma campanha descentralizada.

\section{E como foi feita essa campanha descentralizada?}

Com condutores estaduais. O secretário de saúde local apresentava seu plano dentro das condições estabelecidas pelo comitê específico. Ele tinha que atingir um determinado percentual de cobertura, usar aquele tipo de vacina, não podia usar outro, só a vacina que o ministério indicava. Ao contrário de esperar que a população procurasse pelos serviços, ele tinha que oferecer os serviços à população, onde quer que ela se encontrasse. Se a população menor de cinco anos não está na escola, então é preciso saber como encontrá-la. Onde você encontra a população com menos de cinco anos? Com os pais. O ponto em questão era saber onde estavam as mães e os pais? Esse era o objeto das campanhas. Toda a mobilização foi montada em cima do pai e da mãe como responsáveis. A difusão, na época muito difícil, porque os meios eram muito diferentes, era uma coisa de bater no estômago. Tinha uma 
"A Saúde teve um papel importantíssimo. Passou a ser um mecanismo do Estado autoritário para aproximar-se da sociedade civil." música suave, mas, ao mesmo tempo, aparecia uma criança aleijada, na cadeira de rodas.

\section{Chocante...}

Para um quadro chocante a estratégia foi a de buscar chocar e, ao mesmo tempo, embevecer, trazer à responsabilidade, e informar ao pai e à mãe o que era a pólio e como se podia controlá-la. Portanto, este é o segredo de você conseguir sucesso em qualquer empreendimento. Fazer com que o destinatário da sua atuação seja sujeito dela. E para ser sujeito, o indivíduo precisa compreender o que está ocorrendo. Qual é o problema e como pode ser resolvido. E buscar no Estado os meios para agir. Era isso o que estava em discussão naquela época para essa questão específica.

\section{O senhor cita o dr. Sabin. É fato que ele serviu como um catalisador da equipe?}

Teve esse efeito positivo. Mas, ao mesmo tempo, nos levou a uma polêmica, a uma perda de energia enorme, porque tínhamos que nos defender das acusações da imprensa, que assumiu Sabin como o prêmio Nobel do Brasil. Ele nunca teve prêmio Nobel, mas a imprensa brasileira lhe deu o Prêmio Nobel. Ele era casado com a filha da condessa do Jornal do Brasil.

\section{Talvez também porque ele atacasse um Estado que era...}

Ele atacava um Estado autoritário e, ao mesmo tempo, atacava a falta de responsabilidade desse Estado autoritário com a saúde da população. Isso aconteceu até o dia em que fizemos uma reunião do estado-maior no nosso ministério. Foram palavras minhas naquela reunião: "Ministro, o senhor não deve dizer mais nada. Tudo o que o senhor diz a imprensa deturpa. Deturpa, no mínimo, chamando o senhor de piauiense. Quem é o piauiense que vai contestar o grande prêmio Nobel? Tudo que o senhor disser será inútil." Aliás, eu sempre o alertava para uma questão estratégica fundamental: "Ministro, água de morro abaixo e fogo de morro acima não tem jeito. Deixa a água cair, deixa o fogo acabar. Vai passar. Enquanto isso, vamos nos organizar para fazer a mais vigorosa ação que o poder público já fez no Brasil. Com enorme participação popular e social."

Por sinal, em entrevista para outro projeto da Casa de Oswaldo Cruz, o senhor diz que através da campanha da poliomielite foi possível construir a ponte entre Estado e sociedade...

Com a sociedade civil, sem dúvida nenhuma. A Saúde teve um papel importantíssimo. Passou a ser um mecanismo do Estado autoritário para aproximar-se da sociedade civil. Tanto pelo aproveitamento de profissionais que não tinham acesso ao aparato do Estado (ou, quando tinham, este acesso era limitado pela ação de controle da divisão de 


“Quando
absorvemos o
PNI, colocamos o
programa em
movimento, em
nível de aspiração
social, e não
como uma
necessidade dos
técnicos. Por isso
ele ganhou
expressão ...
Você imagina um
ministério desse
tamaninho, com
muito
conhecimento e
capacidade de
agir, mas com
10\% do
orçamento da
Saúde. Já $90 \%$
estavam no
Inamps.”

segurança), quanto pela abertura para a sociedade, para o indivíduo comum, o pai e a mãe, no caso específico da imunização.

\section{Mas por que esta ação começou com a pólio?}

Porque quando chegamos no ministério vivenciávamos uma epidemia forte, que surgiu nos estados do Paraná e de Santa Catarina. Uma epidemia que já se transformava em endêmica no Nordeste do Brasil. Mas o Sul era o núcleo mais forte, ou mais falante, porque tinha mais poder político para falar.

Eparece, também, que o secretário de Saúde de um dos estados do Sul tomou a iniciativa de divulgar a epidemia, de não esconder...

Essa também era uma posição do ministério. "É assim mesmo, a situação é feia e nós temos uma proposta de ação para ela. Então tu aguardes a nossa ação." Isso era dito. A imprensa que cobria o ministério sempre ficou do lado do ministro e a grande imprensa contra. Lógico, até que a gente virou esse papel quando a água acabou e quando o fogo sumiu.

O governo, então, valorizava essa ponte que o Ministério da Saúde construía com a sociedade?

Muito! Porque nós enfrentamos essa reação da grande imprensa, que agora já começava a mudar de lado. Sempre apoiaram o golpe (golpe militar de 1964). Porque o golpe e a ditadura não se sustentariam sem o apoio da grande imprensa, todos sabemos. Agora, nos ares dos novos tempos, começava a mudar de lado. Nós enfrentamos essa situação sem envolver o resto do governo. Ou seja, o ministério, encapsulado, enfrentou a questão, sem envolver a autoridade do presidente da República.

\section{Mas o presidente não deu sustentação?}

Deu sustentação. Mas nossa estratégia de silêncio para a grande imprensa nos favoreceu. O ministro só falava aos setoristas dos jornais, que eram seus aliados, sabiam o trabalho que a gente vinha fazendo. Não falávamos e nem respondíamos aos ataques e deixávamos correr o tempo enquanto nos organizávamos. Pensávamos: "Quando a água descer e quando o fogo sumir, nós estaremos em campo."

\section{Qual foi a posição adotada com o PNI?}

Quando absorvemos o PNI, não fizemos nenhuma mudança. Colocamos o programa em movimento, em nível de aspiração social, e não como uma necessidade determinada pelos técnicos. Por isso ele ganhou expressão no comitê que dava unidade tática ao ministério, importantíssimo. Posteriormente... Bem, aí eu vou explicar um outro componente da estratégia, que dava sustentação interinstitucional à proposta interna. Quando o ministério alcançou a unidade interna, pôde avançar para construir um núcleo de planejamento estratégico da 
Saúde com características interinstitucionais e até intra-setoriais, que foi a Comissão Interinstitucional de Planejamento e Coordenação na área de Saúde (Ciplan).

\section{Comofuncionava essa instância?}

Você imagina um ministério desse tamaninho, com muito conhecimento e muita capacidade de agir, mas com $10 \%$ do orçamento público da Saúde. Já 90\% estavam no Inamps... Por isso construímos a Ciplan - uma reunião dos secretários-gerais dos ministérios da Saúde, Previdência e Assistência Social e Educação. Depois entraram Trabalho e Indústria e Comércio para tratar da questão das bebidas e do transporte de cargas explosivas. Mas o núcleo era Saúde, Previdência e Educação, cujos três secretários-executivos coordenavam a comissão e traçavam o planejamento estratégico para as três pastas, no que compunha a eles: assistência médica, formação pessoal, hospitais universitários,

“O SUS está com mais de dez anos e o Ministério da Saúde não buscou uma organização intersetorial. Como é que você pode acreditar que política de salário-mínimo é de interesse exclusivo do Ministério do Trabalho? ... O problema da violência como grande criador de demanda para a Saúde. Como a Saúde não tem que participar disso?" especializações e residência médica, que estavam lá no MEC. Então, os assuntos eram tratados à luz de condicionantes estratégicos gerais de atenção à saúde.

\section{Mas era possivel se chegar a um entendimento?}

Foi na Ciplan, por exemplo, que o Risi começou a articular com o Inamps, que compunha a equipe do Ministério do Planejamento, a ação de controle das doenças transmissíveis. Com a estrutura central do Inamps seria impossível conversar. Mas as equipes técnicas do Risi e do Inamps se somavam e suas questões se desdobravam em resoluções com força política. A mesma coisa era feita na área de alimentação e nutrição, na área de saúde da mulher e da criança, em tudo aquilo que tinha a ver com as ações específicas desses órgãos envolvidos na Ciplan. Lamentavelmente desmancharam isso. Nem depois do SUS voltaram a criar, o que é um absurdo completo.

\section{Em sua opinião, faltam, hoje, mecanismos de ação intersetorial?}

O SUS está com mais de dez anos e o Ministério da Saúde não buscou uma organização intersetorial. Como é que você pode acreditar que política de salário-mínimo é de interesse exclusivo do Ministério do Trabalho? Política de salário-mínimo é coisa de subsistência popular, portanto, tem que dar condições para que você aufira condições básicas de saúde. Uma política de saúde ocupacional interessa à Saúde. Ou seja, cuidar da saúde no pátio das empresas é tão importante como cuidar da saúde no Serviço de Saúde, certo? Mesmo assim, não se organizou nada disso. Só se organizou o setor: tripartite. Não se buscou a organização intersetorial. Este é um dos grandes problemas que temos hoje. 
“A criança nascia

e, ao completar a idade da pólio, se não tinha campanha naquele momento, a mãe levava no Serviço e já vacinava. Depois, no Dia Nacional de Vacinação, vacinava de novo. No Dia não importava se a criança já tinha sido vacinada. Todos eram vacinados, como é até hoje e como deve ser.”
Faltam, portanto, ações integradas?

Falta unidade tática de ação. Portanto, a estratégia constitucional não se materializa, não se realiza. Assumem uma postura do tipo: "Não, já temos problema demais", como se o ministério pudesse resolver, sozinho, os nossos problemas. O problema da violência como um grande criador de demanda para o setor de Saúde. Como a Saúde não tem que participar disso? É claro que tem. Tem conhecimento, tem idéia e tem ação pró-ativa a desenvolver conjuntamente. Como é que você vai fazer prevenção dos acidentes de trânsito, sem trazer os profissionais da área de Saúde para discutir? Só com engenheiro de trânsito? Essa é uma realidade. Nós fizemos isso na década de 1980, com a Ciplan. E da Ciplan surgiram comitês interinstitucionais.

\section{Quer dizer, uma articulação ampliada?}

Fez circular mais amplo, trazendo luz para dentro do ministério e levando luz e conhecimento para outras instituições. Não se tratava de donos da verdade, donos da experiência, donos da forma de fazer melhor. Tratava-se de somar para atingir objetivos ainda maiores. É daí que o Ministério da Saúde e as secretarias de Saúde passam a receber recursos do Inamps, que antes não recebiam. Você tinha um sistema de co-gestão. E chegamos, em 1983, ao convênio tripartite, articulando União e estados. Os estados, a Previdência e o Ministério da Saúde, juntos, assinando um único convênio, definindo ações e repasses de recursos. Ou seja, o instrumento importante para você conduzir orçamento. Dinheiro.

\section{Que em 1983 devia ser muito curto...}

Muito curto para tudo. Nos próprios hospitais de algumas secretarias de Saúde não havia dinheiro do Inamps. Os hospitais do Ministério da Saúde, no Rio, não recebiam recursos do Inamps. Os recursos tinham que vir do orçamento próprio. E a assistência média, como se sabe, era da responsabilidade do Inamps, que contratava hospitais privados, mas não usava a estrutura pública do Ministério da Saúde. Quer dizer, isso foi uma coisa conquistada, porque não tínhamos uma ação bem delineada, uma estratégia bem definida, suscetível de ser defendida em qualquer lugar. Tínhamos uma unidade tática estabelecida para fora. E, por isso, outros recursos foram ofertados ao Ministério da Saúde, e em grande quantidade. Apareceu o Banco Mundial, apareceu o Fundo de Apoio à Integração Social (Fais), e depois o Finsocial. O Ministério da Saúde era grande usuário desses fundos. Nós éramos convidados a participar das linhas de crédito, pelas respostas que oferecíamos. Não andávamos de pires na mão. 


“Não era fácil
chegar no
mercado
internacional e
comprar 35
milhões de
vacinas. Quando
apareceram os
fungos na vacina
da lugoslávia, nos
perguntamos:
será que o
controle
internacional e a
segurança que
nós tínhamos no
laboratório
vistoriado pela
OMS são
suficientes? Ficou
evidente que
precisávamos do
nosso controle
interno.”

As campanhas, principalmente a partir da de pólio, promoveram um crescimento significativo do uso de vacinas.

Exatamente. Mesmo as mantidas sob regime de rotina exclusiva, pela dinâmica que as pessoas ganharam com a pólio. Com a campanha da pólio os epidemiologistas, as secretarias de Saúde e as pessoas que trabalhavam nos serviços de saúde viram uma realidade diferente, a solidariedade social. Isso era uma alegria de viver. Veja: as pessoas ganhavam pouco, mas você chegava em qualquer serviço de saúde e as via alegres e felizes, por terem visualizado novas formas de fazer o seu trabalho. Passaram a falar com as mães, com os vizinhos. Não por acaso este foi um dos fatores relevantes para a elevação de cobertura de outras vacinas, que não entraram em dias nacionais de vacinação. E o dia nacional ainda tinha o rádio, que estimulava a rotina daquela vacina e de outras.

\section{Quer dizer, ampliou-se a cobertura?}

Sim, porque a criança nascia e, ao completar a idade da pólio, se não tinha campanha naquele momento, a mãe levava no serviço e já vacinava contra a pólio. Depois, no dia Nacional de Vacinação, vacinava de novo. Porque no dia não considerava se a criança já tinha sido vacinada. Todos eram vacinados, como é até hoje e como deve ser.

Qual o impacto desse crescimento nos órgãos do Estado específicos da imunização? Afinal, ao que se sabe as estruturas da vigilância e de controle de qualidade eram bem precárias...

Bastante precárias. Mas vejamos, por exemplo, o impacto entre os epidemiologistas que compunham os núcleos das secretarias de Saúde. Antes, eles ficavam lá, jogados no canto, só traziam problemas para os secretários. Com a repercussão dos dias nacionais, eles passaram a ser as pessoas que traziam soluções para as secretarias. Aumentou o valor social dessas equipes, pequenas, porém resolutas, que vestiam a camisa e batalhavam, dia e noite. As pessoas trabalhavam. Eu visitava muitas secretarias de Saúde e as pessoas varavam noite, estimuladas...

\section{Houve, então, uma valorização do servidor da Saúde?}

Pelo prestígio adquirido no trabalho, no encontro com a população, com a sociedade civil. Isso valoriza as pessoas. E esse prestígio repercute na ascensão dentro das estruturas burocráticas. Os núcleos de epidemiologia passaram a ser considerados pelos secretários, pelos governadores. Qual era o governador de estado que, na época, quando visitava uma regional, não se acompanhava daquelas meninas da Epidemiologia da Secretaria de Saúde? Chamavam pelo nome: "Fulana! Cadê Fulana?" Para dar sustentação aos discursos políticos deles. Era um status político. Antes, tinham o status técnico, mas não tinham o político e, portanto, não tinham apoio, recursos, e capacidade de mobilizar nada, nem ninguém. 
Mas como se realizava o controle de qualidade, das vacinas? A crise da vacina da Iugoslávia fez acender a luz vermelha?

O controle era disperso, seguindo padrões diferentes. A primeira coisa que fizemos foi articular a questão dos insumos numa estrutura de comissões, uma organização chamada Comissão de Articulação (Comart). A Comart era formada por técnicos da Fiocruz e da Ceme. Não era mais aquela Ceme poderosa, do início do PNI, vinculada à Presidência da República, aparecendo como comprador de vacina, como supridor de vacinas para o Ministério. Vacinas que morriam nos estoques, sem uso...

\section{Oque mudou?}

Essa Comart Ceme-Fiocruz funcionava no Rio, dentro da Fiocruz, porque era por lá que chegava a maior parte das vacinas, que eram importadas. Então, já que era assim, nós resolvemos concentrar e estabelecemos: "Vacina só entra pelo Rio, pela Fiocruz. E a Fiocruz assume a responsabilidade de receber, conferir, armazenar, identificar lotes para análise e promover a realização das análises."

\section{Isso aconteceu no início dos anos 1980?}

Entre 1980-82, porque a vacina da Iugoslávia nos chamou a atenção. Nós não podíamos confiar totalmente. Mas para fazer a campanha nós confiamos. Não tínhamos onde buscar vacina no Brasil, compramos de quem tinha. E, mesmo assim, foi muito difícil comprar. Não era fácil chegar no mercado internacional e encomendar 35 milhões de doses de vacinas. E quando apareceram os fungos na vacina da Iugoslávia, nós nos perguntamos: será que o controle internacional e a segurança que nós tínhamos no laboratório vistoriado pela Organização Mundial de Saúde (OMS) são suficientes? Ficou evidente que precisávamos do nosso controle interno.

\section{É aí que surge o projeto do Instituto Nacional de Controle de Qualidade em Saúde (INCQS)?}

Aí nasce a idéia de construir o INCQS. A Secretaria de Vigilância Sanitária tinha um laboratório no Rio chamado LCCDMA — até a sigla é esquisita - o Laboratório Central de Controle de Drogas, Medicamentos e Alimentos. Mas a estrutura, em última análise, era coercitiva. Nós precisávamos de estruturas capazes de aperfeiçoar o controle em pleno vôo, porque senão a gente não tinha vacina. Então não podíamos agir só fechando, baixando, batendo. Tínhamos que dosar a estratégia. Caso contrário, não teríamos uma única dose de vacina. 
"Quem só

fiscaliza

dificilmente

promove

mudança, porque

tem que seguir a

lei, autuar.

Queríamos uma

instituição que

entrasse nas

empresas para

corrigir métodos

e aperfeiçoar a

qualidade. $\mathrm{O}$

INCQS entrou

com essa

filosofia, apesar

de também ser o

laboratório de

referência para as

análises

contestatórias do

sistema de

fiscalização."
O dr. Vinicius da Fonseca não chegou a fazer um acordo para levar esse laboratório para a Fiocruz?

Mas não conseguiu, porque a Vigilância Sanitária não abria mão. Era uma estrutura de laboratório que analisava amostras mandadas pelo Sistema de Vigilância Sanitária. Ou seja, não tinha a capacidade de induzir o aperfeiçoamento, só de punir. E aí punia um lote de medicamento, mas não tinha nenhuma capacidade de agir sobre a empresa que produziu aquele lote, para que fossem alteradas as condições que geraram o erro, o lote mal produzido. Lote não existe ao acaso. Existe por condições objetivas de produção. Problemas de má qualidade de matérias-primas, má qualidade de manipulação, descumprimento de técnicas específicas.

\section{Esse laboratório tinha, portanto, uma ação muito limitada?}

Era um órgão burocrático. Recebia amostras, analisava, selava, lacrava. Aí o cara se defendia, abria outra amostra. Era um órgão que não tinha capacidade de induzir. Já o INCQS foi uma criação da nossa administração e o próprio nome surge em contraposição a essa idéia de só punir. Quem só fiscaliza dificilmente tem capacidade de promover, porque tem que seguir a lei, tem que autuar. Nós queríamos entrar nas empresas com outra visão. Não era mais o 'autuador' que entrava. Era a Instituição que entrava para corrigir métodos e aperfeiçoar a qualidade. O INCQS tinha mais facilidade de penetrar nos lugares, porque entrava com essa filosofia, apesar de também ser o laboratório de referência da Vigilância Sanitária para as análises contestatórias do sistema de fiscalização.

\section{Como foi estruturar o INCQS dentro da Fiocruz?}

Àquela altura, tínhamos a Fundação Oswaldo Cruz inteiramente articulada no processo do Ministério. Não era mais uma estrutura apática, que você conversa às vezes. A Fundação Oswaldo Cruz participava de todos os comitês, pela função de pesquisa, pela função de capacitação de recursos humanos. Era partícipe ativa da política do ministério, estava envolvida em todas as nossas ações, com seus melhores profissionais. Quando chegou a hora, optamos: "Vamos fechar o LCCDMA. É uma decisão política." Logicamente, nasceu aí um conflito, meu principalmente, com a Secretaria de Vigilância, que não aceitava. Mas nós reafirmamos que ele seria fechado, porque sua atividade era desnecessária e enganosa para a sociedade. Não tinha técnica, equipamentos, materiais e nem poder político. Estava isolado, sem poder oferecer tudo aquilo que uma instituição como a Fundação Oswaldo Cruz proporcionaria, ou seja, um ambiente de especulação, típico de uma instituição de pesquisa e preparação de recursos humanos. Muito diferente da prática de perseguir empresas, geralmente para... ganhar o bônus, que era o que fazia o LCCDMA. 
E alimentando a banda podre, não é?

A banda podre. Quer dizer, "Ah, como é que vai fazer?" "Não, as análises são feitas. Não tem laboratório na Fiocruz? Não tem laboratórios em São Paulo? Não temos os laboratórios centrais das secretarias de Saúde? Manda para lá. Quando tivermos alguma dúvida, mandamos para exterior. Pedimos apoio da OPAS." Enquanto isso, a Fiocruz treinava seu corpo técnico no exterior.

\section{Isso entre 1980-82?}

Em 1982. Nesta época, os primeiros trinta componentes do INCQS voltam com os seus mestrados do exterior. Para você ver quanta decisão foi tomada antes de mandar trinta pessoas para o exterior fazer mestrado na área de controle!

\section{Eeles foram para uma instituição específica?}

A Fiocruz escolheu, com o apoio da OPAS, onde essas pessoas deveriam fazer seus mestrados. Veja bem: não foram estágios. Foram mestrados. Todos eram muito jovens, recém-formados, precisavam primeiro ter uma qualificação melhor do ponto de vista profissional, para depois ganharem suas especializações. E esse time voltou trazendo, no bojo, um componente importantíssimo: a ousadia do jovem preparado. O jovem é abusado por natureza. Preparado, ele enfrenta as circunstâncias, compra a briga. Porque lá fora eles deixaram pessoas que foram seus tutores, com quem eles trocavam correspondência e, logicamente, bebiam experiências. Uma rede de relações que não estava escrita em lugar nenhum, mas que existia, e o ambiente da Fiocruz, uma instituição aberta para o mundo, estimulava isso. Encontramos, então, uma pessoa para comandar todo esse processo...

\section{Quem foi essa pessoa?}

Peixoto. Dr. Peixoto. Era um engenheiro químico, formado na boa Escola de Engenharia Química da UFRJ. Hoje é a melhor do país. Foi tirado de lá, também jovem, ousado, malcriado. Como isso surgiu? Com peso político. Escolher, confiar e sustentar os atos deles, muitas vezes tomados intempestivamente, num certo arbítrio. Mas acreditávamos que só assim ele iria se capacitar para o trabalho e, depois, liderar uma enorme equipe e a constituição de uma organização como aquela. Pessoa difícil de relacionamento, como são os engenheiros químicos. Mas tínhamos a Comart, que passou a exercer controle absoluto das entradas de vacina. Acabamos com aquela história de "a Secretaria de Pernambuco comprou vacina no leste da Polônia".

\section{A entrada da vacina era pelo Rio?}

A entrada tinha que ser pelo Rio. A vacina só era liberada pela Fiocruz. Ao mesmo tempo, essa Comart identificou todas as falhas do sistema de conservação, do tipo de transporte que devíamos usar. 
Tudo isso não se sabia. Botava-se gelo no isopor e despachava pela Varig. Passamos, a partir disso, a ter contêineres, lacrados e selados, que saíam com números específicos para cada estado. Não ia um cara que passava no Rio, pegava o isopor e levava no vôo da noite. Eu conheci muito isso em vacina...

A Comart e o INCQS tiham por missão vencer toda a precariedade da área...

Era muito precário. Faltava luz em um dia e, no outro, a vacina voltava a ser usada, do mesmo jeito. E tínhamos muitas quedas de energia naquela época. Tudo isso a Comart identificou. E a secretaria geral aqui, com um grupo específico para proporcionar essa condição lá no estado. Criamos um programa de cooperação técnico-administrativa para as secretarias de Saúde dos estados.

\section{Como foi a instalação do INCQS?}

O INCQS ocupou um laboratório que o Vinícius tinha começado a montar, vazio. Com os equipamentos comprados e tudo embrulhado. Aí a Fiocruz contratou o Peixoto para coordenar esse processo. Peixoto identificou, tratou, começou a montar aquele edifício bonito que está lá. Começou a botar o layout dos equipamentos, analisar todos os negócios dos fornecedores, chamar as firmas que forneceram para a implementação dos laboratórios, tudo isso estava lacrado. Enquanto isso, a turma estava no exterior.

\section{Toda essa obra foi realizada na época do dr. Vinícius, e a abertura na} gestão do Guilardo?

Exatamente. Mas nós demos vida àquilo. Aquilo não tinha vida, estava fechado, cheio de equipamentos dentro. Criamos o INCQS e abrimos, ainda usando a capacidade laboratorial disposta na própria Fundação IOC, quebrando o galho. Toda vacina era controlada. Não tão bem controlada. Não tínhamos todos os elementos para o controle, mas os testes padrões começaram a ser realizados, a quarentena era realizada, acabou o risco de aplicar vacina com fungo...

E mesmo os laboratórios nacionais, Butantã, Ataulfo de Paiva, dos quais o ministério continuava comprando, passaram a se submeter a esse esquema?

Todos. Tinham que mandar para a central que a Fiocruz montou para cuidar disso - não me lembro mais o nome da unidade que envolvia logística, finanças e elementos da própria Fiocruz. O ministério só dava apoio financeiro.

\section{E lá essas vacinas eram analisadas?}

Analisadas e colocadas em quarentena, depois saíam por lote e nós íamos juntando esses lotes para abastecer as unidades, à medida 
também que íamos mudando a qualidade do transporte, do manejo e do armazenamento nos estados. Tudo isso foi montado, comprado, em pleno vôo. Assim fizemos o PNI funcionar. Com o mínimo necessário. A secretaria geral habilitando os grupos para desenvolver projetos de cooperação técnica com os estados, e comprando geladeiras, freezers, geradores. Até que passamos a ter uma central nos estados, capacitada a receber a vacina se responsabilizar a partir daí. Tudo isso em pleno vôo, montando a estrutura, e o PNI operante.

\section{Como ficam as relaçôes com os laboratórios nacionais?}

Aí começa a surgir o projeto de auto-suficiência, na medida em que nós, com a consciência das limitações de algumas das nossas vacinas, sempre induzimos projetos de pesquisa. Entrava a área de pesquisa aqui para a secretaria geral, o fomentador, que ia lá e dava o dinheirinho para o indivíduo conseguir resultado para resolver aquele problema do componente tal na vacina tríplice. Isso existia. Você estimula uma pesquisa aplicada, efetivamente, para sanar aquele problema imediato, para melhorar a qualidade da vacina. Incentiva a montagem dos laboratórios de controle de qualidade nas próprias unidades produtivas.

Pelo seu relato, depreende-se que a estrutura do INCQS, indutora de qualidade, acaba inspirando o Programa de Auto-Suficiência em Imunobiógicos-o PASNI?

Auto-suficiência, que é oficializada depois que o Arcoverde sai do ministério, mas que já funcionava nessa fórmula que levamos para lá. Nós chamávamos esses laboratórios todos, eles apresentavam as suas possibilidades, as suas necessidades, as suas dificuldades. Fazíamos um programa de sustentação econômica e técnica para eles, ganhando a confiança deles e permitindo, em 1985, se eu não me engano, oficializar o Programa de Auto-Suficiência. Mas nessa época eu já tinha saído do ministério.

Qual a contribuição dessa política, que precedeu o PASNI, para a gestão dos laboratórios nacionais?

Preconizávamos cronogramas de cumprimento de metas. No caso de um laboratório desses, tinham as vacinas, as capacitadas a produzir, cronograma de entrega, que ele poderia cumprir, e as dificuldades para adotar novos métodos e procedimentos de controle que começavam a ser exigidos a partir daquele momento. Isso não era abrupto. Claro, isso trouxe problemas de examinar a linha de produção de alguns laboratórios. Ocorreu. Mas isso ocorria com 
“A Vigilância

Sanitária, associada a todos

os grupos da banda podre da própria indústria. E aí começaram a contestar todos os laudos do INCQS. Muitas contestações foram para arbitragem internacional. $\mathrm{O}$ INCQS ganhou todas." prévio debate, negociação, até que chegava a um ponto em que não dava para continuar.

De alguma forma, o ministério orientava a produção e indicava o padrão de qualidade...

Como foi o caso da produção da vacina de sarampo na Fiocruz. Começou em caráter experimental. A cooperação com o Japão trazia a técnica, o procedimento, a cepa a ser utilizada. Nós fazíamos a planta de produção, envasávamos e controlávamos, a partir daí, a qualidade. Até que passamos a produzir o nosso próprio bulk. Sob a supervisão do fornecedor da tecnologia, que era do Japão. Foi o que se pode fazer na época e produziu-se vacina de sarampo de boa qualidade. Hoje é muito melhor, porque a cada dia você marcha e vai melhorando, sempre quando você tem estímulos para melhorar.

Mudar a política de fiscalização, criando o INCQS, não impôs um enfrentamento político?

O INCQS se manteve porque quando vieram as pressões o secretáriogeral do ministério disse assim: "O INCQS vai continuar e, para mudar isso, vocês têm que passar por cima de mim. Só me tirando do ministério ou me matando. O INCQS é um objetivo meu, particular, que será mantido a ferro e a fogo. Nós apostamos nessa idéia e estamos trabalhando para que ele seja o melhor."

\section{E de onde vinham essas pressões?}

Vigilância Sanitária. Logicamente, associada a todos os grupos da banda podre da própria indústria. E aí começaram a contestar todos os laudos.

Como os senhores enfrentaram essa estratégia da Vigilância Sanitária e setores da industria de contestar os laudos sempre?

Fomos cumprindo. As contestações eram efetuadas, muitas delas foram parar em análises no exterior. O INCQS não perdeu nenhuma contestação no exterior, apesar da jovialidade e da ousadia de sua equipe. Ganhou todas. Toda vez que eles peitaram, nós respondíamos: "Então vamos para a análise internacional. Recomendamos tal instituição. Vocês aceitam?" O poder de arbitragem era feito aí. Designe os seus representantes, o INCQS designa os seus, e vamos mandar as amostras coletadas para esse laboratório. Geralmente isso ia cair lá no FDA (Food and Drug Administration, dos Estados Unidos), um laboratório especializado.

Então, no pano de fundo de toda essa história houve uma guerra contra a corrupção?

Isso foi uma das coisas de maior pressão e desgaste, para mim, dentro do ministério. Essa pressão corrupta dessa Secretaria de Vigilância 
“Produção de
vacina é
estratégia de
segurança
nacional. Vimos

isso na guerra das

Malvinas. Os

fabricantes

britânicos e

americanos de

produtos

sensíveis

fecharam seus

laboratórios na

Argentina. 0

Brasil forneceu

insulina para os

diabéticos

argentinos. E

também plasma,

porque as

unidades deles,

todas

multinacionais,

simplesmente

fecharam as

portas. A

sobrevivência das

pessoas não pode

ficar a mercê do

jogo de mercado

ou dos conflitos

entre potências."
Sanitária, que buscava eventuais excessos de zelo ou ousadias da jovem equipe do INCQS para bombardear a estratégia, que era absolutamente correta. Claro! E por que na Fiocruz? Primeiro, porque lá foi construída a estrutura física. Onde é que nós íamos construir outro prédio daquele? Com que recursos? Você em vez de fazer funcionar ainda ia construir outro? Ia estruturar uma nova organização, uma nova autarquia para se chamar INCQS? Quanto tempo e quanto ia custar tudo isso? Depois, como se beneficiar de todo o conjunto de estruturas laboratoriais que a Fiocruz dispõe, e que você não tem em nenhuma outra instituição? Com defeitos e com virtudes, não tem. Duvido da instituição que tenha o volume do laboratório que tem o IOC. Afora...

\section{Os laboratórios de Far-Manguinhos, de Bio-Manguinhos.}

Quem poderia mais usar isso aî? Onde estaria situado isso? Ainda mais: era uma fundação do próprio ministério, com flexibilidade, autonomia, que tinham as fundações naquele tempo — não tem hoje, mas tinham naquele tempo. ... de autonomia, com seus orçamentos próprios, os recursos entravam, podiam passar de um ano para outro, podiam buscar receitas fora, podiam vender serviços...

Por que, em suas compras, o governo dava preferência aos laboratórios nacionais, mesmo quando sabendo que estes eram muito maisprecários que os estrangeiros?

Era um problema de responsabilidade. Produção de vacina é um assunto de estratégia de segurança nacional. Um país que não tem a capacidade de produzir e controlar suas vacinas estará sujeito a atitudes inconvenientes de outras nações em questões de crise. Vimos isso na guerra das Malvinas. Os fabricantes estrangeiros de produtos sensíveis fecharam seus laboratórios na Argentina. Quem forneceu insulina para diabéticos da Argentina? O Brasil, que adotou posição neutra na guerra, mas assumiu a posição de fornecer produtos farmacêuticos, todos os de uso contínuo, além de sangue e derivados. Quem supriu plasma para a Argentina foi o Brasil, porque as unidades deles, todas multinacionais, simplesmente fecharam as portas. Eram unidades americanas ou britânicas. O que provou, mais uma vez, que nesta questão você tem que dar sustentabilidade à produção nacional, por ser estratégico ao interesse nacional. A sobrevivência das pessoas não pode ficar à mercê do jogo de mercado ou dos conflitos entre potências.

Isso justificaria, inclusive, comprar mais caro uma vacina de pior qualidade?

Evidentemente. Isso aí era assumido às claras pelo Ministério da Saúde. Começamos a controlar as matérias-primas farmacêuticas, pelo mesmo modelo. O INCQS quando começou: "Ah, mas esse cristal 
curto, em nossos produtos só usamos cristais longos." Então o INCQS ia arbitrar se havia diferenças efetivas entre o uso do cristal longo e do cristal curto. O objetivo era dar o xeque-mate nas indústrias que começavam a nascer no Brasil, sob a proteção da Ceme. Nós tínhamos que dar sustentação àquela decisão porque aquela indústria nasceu com recursos do BNDES, com financiamento do BNDES. E a Ceme assumia na época o ponto de equilíbrio desse projeto para começar a funcionar. Eles começavam a produzir até o ponto de equilíbrio do empreendimento industrial. Se ele não conseguisse vender, a Ceme comprava, e fornecia aos laboratórios oficiais, para produção de medicamentos.

\section{O esquema parecido então feito na área de vacina.}

Exatamente. Era você entrar, agir em cooperação técnica com a Ceme, no caso de laboratórios farmacêuticos, no controle de qualidade, em boas práticas de fabricação. Tudo isso você via no andar para dentro do laboratório, público ou privado, que fornecesse medicamentos para a Ceme.

\section{Garantindo a compra?}

Garantindo para que os riscos existentes fossem menores que as vantagens de estimular a produção nacional. Ao mesmo tempo, na área de medicamentos, e os mais capacitados iam para dentro do laboratório, juntos, testar novas técnicas, fazer lotes, experimentar novas técnicas, até que elas passavam lá no controle de qualidade da Fundação Oswaldo Cruz, e aí você entrava em produção de escala. E isso em pleno vôo. Isso é fácil de dizer hoje, mas isso era um contundente processo de desgaste, de emoções, de pressões e contrapressões, que são normais, só que eram assumidas.

E como ficava o esquema da licitação pública? Os laboratórios concorrentes não protestavam contra essa política?

Comprávamos direto. E o preço era estabelecido em função das planilhas de custo e comparados aos do mercado internacional, fornecidos pela OMS. Então você tinha gradientes aí que você assumia como estímulo à produção nacional. O ministério pagava.

Hoje a questão se coloca na economia de escala. Um laboratório internacional que vende para ofundo rotatório tem mais condição de oferecer preço menor que o laboratório nacional...

Hoje a Funasa atua nos preços do fundo rotatório. Normalmente, nós fazíamos a adição de preço, em função dos custos. E eram observados também os custos atinentes ao domínio tecnológico. Isso aí não se paga. 
"Collor acabou com a Interbrás, a trading do sistema Petrobras que adquiria insumos para os laboratórios nacionais. Você imagina o que é um laboratório nacional tendo que comprar insumo no exterior, sozinho? A Ceme se apoiava na Interbrás para comprar essas matérias-primas para os laboratórios privados nacionais. Isso é visão de política industrial."
Hoje, qual o fôlego dos laboratórios nacionais para realizar investimentos?

Hoje o Ministério da Saúde está num programa à parte. Um programa de financiamento desses projetos de investimentos. Mas não tem o overhead de desenvolvimento tecnológico que se adotava à época, inclusive com laboratórios privados, na área de medicamentos, fornecedores da Ceme. É inacreditável que você faça uma licitação de laboratórios privados, um laboratório nacional ganhe a licitação, você vai para dentro dele com uma equipe para verificar todos os condicionantes, e, posteriormente, não dê um adicional para permitir que ele aperfeiçoe a sua produção e a sua produtividade, que será transferida à população brasileira, com laboratórios melhores, de melhor qualidade. $\mathrm{Na}$ época existia essa posição do governo brasileiro. O Ministério da Indústria e do Comércio, a Central de Medicamentos e o Ministério da Saúde atuavam organicamente, em conjunto, sobre isso. O Ministério da Indústria e do Comércio tinha a responsabilidade de definir os incentivos financeiros ou fiscais que poderiam ser utilizados e a Ceme tinha que bancar as compras.

\section{Com recursos da Presidência? \\ Presidência. O Ministério da Saúde...}

\section{Presidência ou Previdência?}

Presidência, primeiro, e Previdência, depois, também. Ela tinha essa responsabilidade. O BNDES, ao financiar um projeto, tinha o aval do Ministério da Indústria e da Ceme, e garantias que lhe eram dadas como instituição financeira. Queria ter a certeza de receber de volta o dinheiro investido. Esse modelo acabou no governo Collor e, junto com ele, acabou uma grande quantidade de empresas nascentes, novas, empresas tecnológicas, criadas com esse esforço.

\section{Quer dizer, desmantela-se a política industrial do setor?}

O Ministério da Economia acabou com a Interbrás, a trading do sistema Petrobras que estava sendo utilizada, para adquirir insumos para os laboratórios nacionais. Isso é visão de política industrial. Você imagina o que é um laboratório nacional tendo que comprar insumo no exterior, sozinho? A Ceme se apoiava na Interbrás para comprar essas matérias-primas para os laboratórios privados nacionais.

\section{Eesse esquema foi desmontado?}

Acabou. A primeira medida do governo Collor foi acabar com a Interbrás, que fazia operações muito boas para o país. Porque a Interbrás trocava recursos, trocava café por insumos farmacêuticos, por exemplo. Não entravam divisas. Esse era o esquema balizado em procedimentos do Ministério das Relações Exteriores, em cooperação com alguns países 
do Leste Europeu, bons produtores de matérias-primas farmacêuticas, e também a Îndia. Então você tinha os acordos comerciais do Brasil, em que não havia troca de divisas. Fazia encontro de produtos, produtos da exportação, com produtos da pauta de importação brasileira. Olha que esquema inteligente de política industrial. Não reclamem hoje dos governos militares, sobretudo do Geisel, que tinha uma política industrial competente. Não é à toa que somos auto-suficientes em indústria química de base. Como é que isso aconteceu? Você praticamente criando a empresa sob a égide do governo, contratando os seus técnicos para colocar lá a serviço da empresa, buscando os apoios, os acordos comerciais do Itamaraty, usando como instrumento de disseminação a Carteira de Comércio Exterior do Banco do Brasil, presente no mundo inteiro, a Cacex, que também foi extinta.

“Se o INCQS não
estivesse na
Fiocruz, teria
sido extinto,
como foram a
Ceme, o Inamps
e tantas outras
instituições
brasileiras, com
enorme acervo e
experiências. A
Fiocruz
sobreviveu
porque manteve
sua unidade
interna.”

O senhor se referiu à licitação internacional para a compra da vacina da pólio como "um complicador". Por quê??

Não foi licitação.

\section{Nãofoi licitação?}

Primeiro, não havia capacidade internacional para nos atender. Por isso fomos buscar acordos bilaterais com vários países. Com a Itália, com a Iugoslávia. Então usamos a diplomacia do Itamaraty para a negociação comercial, por sua vez apoiada pelo Banco do Brasil. Nisso aí entrava o Ministério da Saúde como motivador para o Estado italiano na sua relação com as suas empresas, privadas ou públicas. Ou com o governo da Iugoslávia. O Itamaraty articulava com as empresas fornecedoras de vacina, já identificadas pela OPAS, pela OMS... E os governos desses países tiveram que investir nessas empresas para que elas pudessem botar sua produção em atividade contínua, em função do volume de vacina que pedíamos. Porque eles tinham seus fornecedores habituais e você tinha os seus demandantes habituais: o fundo rotatório e os países. Mas 35 milhões de doses de vacinas, para produzir para junho e para agosto, mais $35 .$.

\section{De repente?}

De repente. Pelos bons olhos das autoridades sanitárias brasileiras, que em determinado momento resolvem usar setenta milhões de doses de vacina de pólio no ano. Então foi negociação, comandada pela embaixada brasileira e sustentada na garantia da carta de crédito do Banco do Brasil, aceita em qualquer operação internacional. Não usávamos o empenho do Ministério da Saúde do Brasil, que é como acontece nas licitações. 
Por que setenta milhões de doses?

Tínhamos vinte milhões de crianças, mas sabíamos que ia haver um grande desperdício, pela falta de prática, pelo armazenamento inadequado. Assegurávamos, assim, capacidade armazenada para prover faltas emergenciais. Essa foi a grande logística do dia.

Esse empreendimento deveria contar com apoio grande do próprio presidente, porque mobilizava recursos consideráveis, ou não?

Não. A vacina era baratíssima. Não era um investimento tão forte.

Mas existia um investimento politico. Se vocês dessem com os burros n'água...

Estávamos perdidos. Apostamos tudo. E evidentemente, num governo autoritário, o presidente da República se resguarda de tudo isso. Dá o voto de confiança ao seu ministro da área e determina a outros mecanismos que o apóiem, para que a política governamental não naufrague. Mas a responsabilidade é do ministro da Saúde.

Que avaliação o senhor tem, hoje, da sua experiência no ministério e da contribuição efetiva à política de saúde pública brasileira?

Não posso avaliar as decisões que tomamos. O poder de analisar se elas foram absolutamente corretas ou se elas foram as melhores não pertencem a mim, ou à equipe que esteve comigo no Ministério da Saúde. Cabe, de fato, a outras pessoas. Eu tenho que dizer como fizemos e os resultados que alcançamos com essas decisões. Poderíamos ter tido decisões melhores? Claro que sim. Poderíamos ter definido outras prioridades? Poderíamos. Fizemos muito pouco para a hanseníase. Fizemos muito pouco para a tuberculose. Mas fizemos muito para a assistência da saúde da mulher e da criança, fizemos muito para doenças derivadas do sangue, para endemias como o mal de Chagas, que praticamente tudo que a gente montou na época foi fundamental para que hoje você tenha esse quadro de quase pacificidade na questão da doença de Chagas. Foram funções geradas no nosso tempo, portanto vale a pena compreender, porque nós não tínhamos tempo para escrever tudo isso. Nós tínhamos que atuar. Chegamos até o fim do mandato do presidente.

O senhor se intitula como um homem de esquerda. Como foi colaborar para um governo de ditadura militar?

Considerei sempre a minha formação de homem de esquerda como um elo do processo de abertura política do Brasil, porque a Saúde serviu a isso. A Saúde se colocou como instrumento de pacificação entre sociedade civil e Estado. Talvez um elo pequeno, nessa imensa corrente de fatores agregados, mas colocamos esse elo lá, que era o respeito à minha vida e à minha história de homem de 
esquerda no Brasil, trabalhando num governo liderado por um militar, ainda dentro do esquema da ditadura militar existente na época, mas já vivenciando um processo de abertura política com o general Figueiredo. Foi mais difícil na época do Geisel, quase impossível na época do Médici, mas mesmo assim fizemos vacina. O único projeto de governo na época que tinha o apoio da oposição brasileira. Felizmente, boto isso na minha história também, na minha história da Ceme, onde eu coordenei o plano-diretor. No momento mais obscuro da vida política brasileira, nós conseguimos espaço para construir um plano-diretor para fazer com que você reduzisse a dependência brasileira na área de fármacos. Lamentavelmente, descontinuado quando ele era mais necessário, quando houve a abertura política no Brasil.

Os governos militares montam toda uma estrutura, quer dizer, já se fala num processo de modernização conservadora, sob a égide do autoritarismo...

Mas modernizaram o Estado brasileiro. Tem que se dar esse crédito. Criaram uma enormidade de técnicos, muitos deles em fim de carreira, como eu, passando o bastão...

\section{Etambém instituições...}

Instituições. Se o INCQS não estivesse na estrutura da Fiocruz, teria sido extinto, como foram a Ceme, o Inamps e tantas outras instituições brasileiras, com enorme quantidade de acervo e de experiências. Se analisássemos processos de trabalho do passado, nós não estaríamos sempre inventando a roda. A Fiocruz foi uma das pouquíssimas instituições que sobreviveram a esse sargento do dia na administração pública brasileira porque manteve sua unidade interna.

O senhor se refere ao governo Collor?

Ao governo Collor e a todos os outros. Ao governo Collor, sobretudo, e ao governo posteriormente neoliberal do Fernando Henrique, lamentavelmente, que acabou com a Ceme. Até porque designaram um presidente corrupto. Quer dizer, você bota um presidente malufista para compor o governo e depois fecha o órgão porque ele é corrupto, como se órgãos fossem corruptos. Instituições menores, sem a mesma capacidade de resistência da Fiocruz, morreram. São poucas as que resistiram.

\section{Daquela época?}

Sim, da história do Brasil. Instituições cinqüentenárias e centenárias como a Fiocruz. Pergunta se na Inglaterra algumas dessas instituições morreram? Todas foram ativadas em função dos tempos em que vivem, mas ninguém acaba... London School? Ninguém acaba com o Centro de Controle de Doenças dos Estados Unidos. Alguém 
pensa em acabar com o FDA? Não. As metodologias mudam, as tecnologias mudam e as instituições são recicladas dentro de si próprias para desempenhar novos papéis. No Brasil você acaba com as instituições. Primeiro as empobrece, liquida, os melhores técnicos vão embora. A Sudene é um exemplo. Agora querem fazer de novo. Com que entusiasmo? Um órgão desse surge junto com um líder capaz de conduzi-lo, que era o Celso Furtado. Vai buscar aonde esse líder, agora? Vai inventar? Ou vai pedir ao PMDB que nomeie, ou ao PSDB, ao PPS? Isso não se inventa.

E essa coisa na área de Saúde surge, ressurge, incorpora...

Depois reabre de novo. E você nunca tem nada. Está sempre começando do zero. E mesmo as pessoas que chegam já são outras. Você perdeu equipes. A cada problema que surgia, no ministério, eu estalava o dedo, reunia dez especialistas para discutir conosco soluções para o problema. Vai estalar o dedo hoje. Não surge ninguém. O Estado empobreceu. O objetivo era esse mesmo, eliminar o estado como indutor do desenvolvimento, em beneficio da sociedade. O livre mercado beneficia a sociedade. É vender fastfood.

\section{Ficha técnica}

Entrevistado: Mozart Abreu Lima

Local da entrevista: Sede da Organização Pan-Americana de Saúde, em Brasília

Entrevistador: Carlos Fidélis Ponte

Transcrição: Claudia Peçanha da Trindade

Data da realização da entrevista: 8 de julho de 2003

Data da transcrição: 10 de julho de 2003

Edição: Cristina Chacel 